\title{
WETENSCHAP
}

\section{De rechtspersoon-bestuurder en art. 2:11 BW}

\author{
J.B. Huizink
}

1. In deze bijdrage zal ik kort de werking van art. 2:11 van het Burgerlijk Wetboek (BW) bespreken, ingaan op enkele - vermeende - knelpunten, en zal ik proberen een antwoord te geven op de vraag naar de effectiviteit van de regeling. Daar is aanleiding toe, nu de Hoge Raad ruim een jaar geleden een belangrijk arrest over de reikwijdte van de bepaling heeft gewezen. In HR 17 februari 2017, ECLI:NL:HR:2017:275, NJ 2017/215 m.nt. Van Schilfgaarde (Le Roux Fruitexporters) werd beslist dat bestuurdersaansprakelijkheid op grond van onrechtmatige daad mede door art. 2:11 BW wordt bestreken.

2. In Nederland kunnen rechtspersonen niet als commissaris maar wel als bestuurder van andere rechtspersonen optreden. In geval van een one-tier board moeten de niet-uitvoerende bestuurders evenals commissarissen natuurlijke personen zijn. Met de constructie van de rechtspersoon-bestuurder kan worden voorkomen dat er bij de bestuurde rechtspersoon bij het wisselen van de wacht steeds opnieuw bestuurders moeten worden benoemd en/of ontslagen. Zoals bekend een van de onderdelen in ons rechtsbedrijf waar het nogal eens misgaat. Maar er zijn meer redenen die de figuur van de rechtspersoon-bestuurder aantrekkelijk kunnen doen zijn. ${ }^{1}$ Nederland is niet het enige land dat de figuur van de rechtspersoon-bestuurder toelaat, maar er zijn tal van jurisdicties die een verbod op de figuur van de rechtspersoon-bestuurder kennen. ${ }^{2}$

3. Door een rechtspersoon in plaats van een natuurlijk persoon tot bestuurder van een rechtspersoon te benoemen zou men bestuurdersaansprakelijkheid kunnen ontlopen. Denk aan de veelvoorkomende figuur waarbij iemand zijn persoonlijke holding aandeelhouder-bestuurder laat zijn bij de vennootschap waarin de activiteiten worden uitgeoefend. Art. 2:11 BW beoogt het ontlopen van aansprakelijkheid door middel van dit soort constructies tegen te gaan door te bepalen:

'De aansprakelijkheid van een rechtspersoon als bestuurder van een andere rechtspersoon rust tevens hoofdelijk op ieder die ten tijde van het ontstaan van de aansprakelijkheid van de rechtspersoon daarvan bestuurder is.'

1 Zie voor een overzicht van de voor- en nadelen van de rechtspersoon-bestuurder C.E.J.M. Hanegraaf, Art. 2:11 BW, doorgeefluik van bestuurdersaansprakelijkheid. Hoe diep kan een bestuurder vallen? (diss. Leiden; Uitgaven vanwege het Instituut voor Ondernemingsrecht, nr. 106), Deventer: Wolters Kluwer 2017, p. 35 e.v.

2 Zie voor een overzicht Hanegraaf 2017, p. 28 e.v. 
De aansprakelijkheid van de rechtspersoon-bestuurder rust dus tevens op de zo ook wel aangeduide tweedegraadsbestuurder of tweedegraadsbestuurders, als dat er meer zijn. Bovendien grijpt de regeling door, in dier voege dat als de tweedegraadsbestuurder eveneens een rechtspersoon is, de aansprakelijkheid opnieuw gelegd wordt bij zijn bestuurders-natuurlijke personen. Enzovoort. ${ }^{3}$

4. Zo eenvoudig en zo logisch de bepaling bij eerste lezing lijkt, zo ingewikkeld blijkt zij bij verdere doordenking. Ik noem een aantal vraagpunten, waarvan er sommige inmiddels wel en andere (nog steeds) niet opgehelderd zijn:

- Algemeen wordt aangenomen dat in art. 2:11 BW uitsluitend gedoeld wordt op uit de wet voortvloeiende aansprakelijkheid. Maar dan komt het: alleen aansprakelijkheid op grond van Boek 2 BW of ook daarbuiten, bijvoorbeeld op grond van art. 6:162 BW?

- Ziet art. 2:11 BW ook op rechtspersonen die weliswaar geen bestuurder, maar wel feitelijk beleidsbepaler van een rechtspersoon zijn?

- En in het verlengde daarvan: kan de krachtens art. 2:11 BW op de tweedegraadsbestuurder rustende aansprakelijkheid worden uitgebreid tot personen die aangemerkt kunnen worden als feitelijk beleidsbepaler bij de rechtspersoon-bestuurder?

- Hoe is het gesteld met de mogelijkheid van de tweedegraadsbestuurders om zich te disculperen? En maakt het dan nog verschil of er één of meer tweedegraadsbestuurders zijn?

- Hoe werkt art. 2:11 BW uit als de rechtspersoon-bestuurder een rechtspersoon naar buitenlands recht is?

5. Alvorens nader op deze vragen in te gaan, graag de aandacht voor het volgende. Volgens wetsvoorstel 34491 tot wijziging van het Burgerlijk Wetboek in verband met de uniformering en de verduidelijking van enkele bepalingen omtrent het bestuur en de raad van commissarissen van rechtspersonen (Wet bestuur en toezicht rechtspersonen) zal art. 11 ingrijpend worden gewijzigd. De regeling van de rechtspersoon-bestuurder in het huidige art. 11 zal worden overgebracht naar art. $9 \mathrm{~b}$ lid 2 . In het voorstel van wet worden vooralsnog geen wijzigingen voor art. 2:11 BW voorgesteld. Zoals ik elders heb aangegeven, is de voorgestelde 'reshuffling' van Boek 2 BW, waarbij allerlei bepalingen uit de titels 2 en 3 naar de algemene titel worden overgebracht, opdat zij zich mede uitstrekken tot andere rechtspersonen dan de kapitaalvennootschappen - zoals de vereniging en de stichting - een onzalig idee. ${ }^{4} \mathrm{Ik}$ hoop vurig dat de wetgever op dit punt alsnog tot inzicht komt en de samenhang tussen de verschillende bepalingen over bestuur en toezicht bij de kapitaalvennootschappen niet verloren zal laten gaan. Dat is ook niet nodig, zoals ik in het preadvies heb proberen uiteen te zetten.

3 Zie voor een overzicht van de wetsgeschiedenis mijn commentaar op art. 2:11 BW in de Groene Serie Rechtspersonen.

4 J.B. Huizink, Bestuur en toezicht bij rechtspersonen, mede in de semipublieke en non-profitsector (Preadvies van de Vereeniging 'Handelsrecht' 2016), Zutphen: Uitgeverij Paris 2016. 
6. Terug naar art. 2:11 BW. Is art. 2:11 BW ook van toepassing als de rechtspersoon-bestuurder zich schuldig maakt aan een onrechtmatige daad? Dat dit niet het geval zou moeten zijn, is laatstelijk uitvoerig en met de nodige literatuur- en jurisprudentieverwijzingen betoogd door Lennarts in de bundel Aansprakelijkheid van bestuurders en commissarissen. ${ }^{5}$ Lennarts is, zoals zij zelf op p. 174-175 aangeeft, ingehaald door de Hoge Raad. In HR 17 februari 2017, ECLI:NL:HR: 2017:275, NJ 2017/215 m.nt. Van Schilfgaarde (Le Roux Fruitexporters) werd onder meer overwogen dat art. 2:11 BW is ingevoerd als minder vergaand alternatief voor een verbod op een rechtspersoon als bestuurder, bij welk alternatief als het ware wordt heen gezien door de rechtspersoon-bestuurder en naast deze ook zijn bestuurders aansprakelijk worden in de gevallen waarin de wet aansprakelijkheid van bestuurders regelt. En vervolgens, na verwijzing naar enkele relevante passages uit de wetsgeschiedenis:

'3.4.3 Uit het voorgaande volgt dat art. 2:11 BW van toepassing is in alle gevallen waarin een rechtspersoon in zijn hoedanigheid van bestuurder aansprakelijk is op grond van de wet. Daaronder valt ook de aansprakelijkheid van een rechtspersoon-bestuurder die is gebaseerd op art. 6:162 BW. Deze aansprakelijkheid rust dan tevens hoofdelijk op ieder die ten tijde van het ontstaan van de aansprakelijkheid van een rechtspersoon-bestuurder daarvan bestuurder is. Dit betekent dat voor vestiging van de aansprakelijkheid van een bestuurder van een rechtspersoon-bestuurder niet de aanvullende eis geldt dat de schuldeiser stelt, en zo nodig bewijst, dat ook die bestuurder persoonlijk een ernstig verwijt kan worden gemaakt.'

Dat lijkt heftig, maar dan:

'Uit de aard van de bestuurdersaansprakelijkheid op grond van art. 6:162 BW volgt echter wel dat als een rechtspersoon-bestuurder aansprakelijk is op die grond, een bestuurder van die rechtspersoon-bestuurder aansprakelijkheid op grond van art. 2:11 BW (alsnog) kan voorkomen door te stellen, en zo nodig te bewijzen, dat hem persoonlijk geen ernstig verwijt kan worden gemaakt van de gedragingen waarop de aansprakelijkheid van de rechtspersoonbestuurder is gebaseerd. Deze bewijslastverdeling doet recht zowel aan de ratio van art. 2:11 BW als aan de vereisten voor bestuurdersaansprakelijkheid op grond van art. 6:162 BW.'

Ik vind dat de motivering de beslissing kan dragen. Natuurlijk, men kan op goede gronden aan de beslissing van de Hoge Raad afdoen, ${ }^{6}$ maar de beslissing brengt duidelijkheid en met de uitkomst valt - ook voor tweedegraadsbestuurders -

5 M.L. Lennarts, “Piercing the corporate director" - over de (on)zin van art. 2:11 BW en art. 106A lid 2 FW', in: G. van Solinge, J. van Bekkum, N. Kreileman \& B.A. Schuijling (red.), Aansprakelijkheid van bestuurders en commissarissen. Nadere terreinverkenning in een uitdijend rechtsgebied (Serie vanwege het Van der Heijden Instituut, deel 140), Deventer: Wolters Kluwer 2017. 
mijns inziens goed te leven. Zoals altijd blijven er vragen hangen. Zo lijkt het erop dat de Hoge Raad - al dan niet bewust - op de tweedegraadsbestuurders de door mij verworpen letterlijke interpretatie van art. 2:9 BW, zoals de bepaling luidt sinds de Wet bestuur en toezicht, loslaat. Immers, naar de letter van de wet kunnen bestuurders die ex art. 2:9 BW worden aangesproken, zich disculperen door te stellen (en te bewijzen) dat hen van het onbehoorlijke bestuur geen ernstig verwijt treft. ${ }^{7}$ In deze zin ook NJ-annotator Van Schilfgaarde (nr. 14). Zie over dit punt ook - maar dan radicaal anders benaderd - Vetter, die zich juist vanwege het verschil tussen de collectieve aansprakelijkheid ex art. 2:9 BW (en art. 2:138/248 BW) en de persoonlijke aansprakelijkheid ex art. 6:162 BW over de lijn van de Hoge Raad verwondert. ${ }^{8}$

7. Dan nu de tweede vraag: ziet art. 2:11 BW ook op rechtspersonen die weliswaar geen bestuurder maar wel feitelijk beleidsbepaler van een rechtspersoon zijn? Over het antwoord op deze vraag is eveneens het nodige te doen geweest. ${ }^{9}$ Haar betekenis is in die zin geringer dan sommigen denken, nu de beleidsbepaler slechts bij de aansprakelijkheid in art. 2:138/248 BW kan voorkomen. Als bijvoorbeeld een tweedegraadsbestuurder wordt aangesproken omdat de rechtspersoonbestuurder in strijd met art. 2:9 BW heeft gehandeld, komt men aan de WBA-aansprakelijkheid ex art. 2:138/248 BW niet toe. Hoe dat ook zij, het arrest HR 14 maart 2008, NJ 2008/466 m.nt. prof. mr. J.M.M. Maeijer en prof. mr. H.J. Snijders, JOR 2008/152 m.nt. Y. Borrius (Blankenhoef) heeft uitkomst gebracht. Volgens de Hoge Raad hebben art. 2:248 lid 7 en 2:11 BW beide de strekking misbruik van rechtspersoonlijkheid te voorkomen. Voor de toepassing van art. 2:11 BW maakt het daarom geen verschil of de op grond van art. 2:248 BW jegens de boedel aansprakelijke rechtspersoon formeel bestuurder dan wel beleidsbepaler in de zin van het zevende lid van die bepaling van de gefailleerde rechtspersoon is. Een en ander laat natuurlijk onverlet dat de bestuurders van de beleidsbepalende rechtspersoon zelfstandig als beleidsbepaler in de zin van het zevende lid van art. 2:138/248 BW kunnen worden aangemerkt.

8. De derde vraag was al eerder in het niet altijd even goed begrepen arrest Montedison ontkennend beantwoord. Zie HR 28 april 2000, NJ 2000/411 (Montedison):

'4.14 (...) Volgens art. 2:11 rust de aansprakelijkheid van een rechtspersoon als bestuurder van een andere rechtspersoon op ieder die ten tijde van het ontstaan van de aansprakelijkheid van de rechtspersoon daarvan bestuurder is. Een verdere uitbreiding van de aansprakelijkheid tot degene die het beleid

7 Ik verwijs verder naar de discussie in WPNR tussen Assink en mijzelf, waarover W.A. Westenbroek, Bestuurdersaansprakelijkheid in theorie (diss. Rotterdam; IVO-reeks, deel 108), Deventer: Wolters Kluwer 2017, p. 293 e.v.

8 H.J. Vetter, 'Waarom zou de aansprakelijkheid wegens onrechtmatige daad zijn uitgesloten?', O\&F (25) 2017, afl. 4, p. 63 e.v. Meer speciaal p. 68-70.

9 Zie voor de verschillende auteurs en hun standpunten Groene Serie Rechtspersonen, art. 11, aant. 
van de aansprakelijke rechtspersoon heeft bepaald of mede heeft bepaald, is in art. 2:11 niet gegeven. Weliswaar is in de art. 2:138 lid 7 en 2:248 lid 7, de in de eerste leden van die artikelen gegeven aansprakelijkheid van bestuurders van naamloze, onderscheidenlijk besloten, vennootschappen in geval van faillissement, uitgebreid tot degene die het beleid van de vennootschap heeft bepaald of mede heeft bepaald, maar deze uitbreiding is daar uitdrukkelijk beperkt tot de toepassing van deze artikelen. Er is geen grond deze uitbreiding bij wege van analogie ook van toepassing te achten in de gevallen waarop art. 2:11 ziet.'

Duidelijke taal en een juiste beslissing zou ik menen. De feitelijk beleidsbepaler van de rechtspersoon-bestuurder die de laatste met een wettelijke bestuurdersaansprakelijkheid opzadelt, ongeacht of dat nu om art. 6:162 BW gaat of om een van de Boek 2 BW-bestuurdersaansprakelijkheden, handelt dunkt mij zelfstandig onrechtmatig jegens de rechtspersoon die door de rechtspersoon-bestuurder waar hij feitelijk beleidsbepaler is, wordt bestuurd.

9. Hoe is het gesteld met de mogelijkheid van de tweedegraadsbestuurders om zich te disculperen? En maakt het dan nog verschil of er één of meer tweedegraadsbestuurders zijn? Voor art. 6:162 BW is die vraag beantwoord door HR 17 februari 2017, ECLI:NL:HR:2017:275, NJ 2017/215 m.nt. Van Schilfgaarde (Le Roux Fruitexporters). Zie onder nr. 6. Maar bij de andere vormen van bestuurdersaansprakelijkheid, zoals art. 2:9 en 2:138/248 BW, en - om maar eens iets anders te noemen - de balansaansprakelijkheid ex art. 2:139/249 BW staat de vraag open, in dier voege dat zij (nog) niet door de Hoge Raad is beantwoord. De wetsgeschiedenis is duidelijk, getuige de volgende passage uit de nota naar aanleiding van het eindverslag: ${ }^{10}$

'Wanneer de wetstekst spreekt van "de aansprakelijkheid van een rechtspersoon als bestuurder", dan kan daarmee niet anders bedoeld zijn dan de aansprakelijkheid met inbegrip van de eventuele mogelijkheden tot disculpatie, die de wetsbepaling waaruit die aansprakelijkheid voortvloeit bevat. Diezelfde aansprakelijkheid rust tevens hoofdelijk op iedere bestuurder van die rechtspersoon-bestuurder.'

Hier is geen woord Frans bij. De woorden van de minister van Justitie sluiten bovendien goed aan bij het arrest Le Roux Fruitexporters.

10. Ten slotte de buitenlandse rechtspersoon als bestuurder van een rechtspersoon. Dienaangaande heeft de Hoge Raad zich eveneens uitgelaten. Zie ik het goed, dan is het algemeen gevoelen over die jurisprudentie niet best. Op grond van art. 10:119 aanhef onder e BW beheerst het op de Nederlandse vennootschap toepasselijke recht onder meer de vraag wie uit hoofde van een bepaalde hoedanigheid, zoals die van bestuurder, naast de vennootschap aansprakelijk is. Dit 
brengt mee dat Nederlands recht als het incorporatierecht van de vennootschap tevens de aansprakelijkheid van de buitenlandse vennootschap als bestuurder van deze vennootschap beheerst en dat art. 2:11 BW binnen deze vennootschapsrechtelijke verhouding van toepassing is. Dit laat onverlet dat de vennootschapsrechtelijke verhoudingen tussen de buitenlandse vennootschap en háár bestuurder(s) worden beheerst door buitenlands recht als het incorporatierecht van de buitenlandse vennootschap. Zie HR 18 maart 2011, ECLI:NL:HR:2011:BP1408, NJ 2011/132 (D. Freight). In gelijke zin: HR 21 juni 2013, ECLI:NL:HR: 2013:CA3958, JOR 2013/238 m.nt. H.L.E. Verhagen. Dit betekent dat wanneer het incorporatierecht van de buitenlandse rechtspersoon-bestuurder van een Nederlandse rechtspersoon geen met art. 2:11 BW vergelijkbare regeling kent, de tweedegraadsbestuurders in beginsel buiten schot blijven. Dit vanzelfsprekend tenzij hun in de schoenen geschoven kan worden dat zij in die hoedanigheid rechtstreeks onrechtmatig tegen de rechtspersoon of gedupeerde derden - meestal onbetaald gebleven crediteuren van de rechtspersoon - hebben gehandeld.

11. Tijd voor een evaluatie. Art. 2:11 BW trad in 1987 als onderdeel van de zogenaamde derde antimisbruikwet in werking. Ik heb het niet exact nagezocht, maar weet uit eigen ervaring dat het bestuurdersaansprakelijkheidsrecht tal van - vaak als zodanig aangeduide - indirecte bestuurders heeft weten te 'pakken'. Bij veel van die zaken heeft art. 2:11 BW een belangrijke rol gespeeld. Daarmee lijkt de bepaling aan haar doel - het voorkomen van ontlopen van aansprakelijkheid door het inzetten van een rechtspersoon als bestuurder - te beantwoorden. Gevallen waarin art. 2:11 BW als zodanig niet kon worden geëffectueerd om in de bepaling zelf, respectievelijk haar redactie gelegen redenen, zijn mij niet bekend. Integendeel, niettegenstaande een op zichzelf duidelijke tekst heeft de Hoge Raad het aangedurfd de werking van de bepaling uit te breiden tot rechtspersonen die feitelijk beleidsbepaler van een andere rechtspersoon zijn en verduidelijkt dat art. 2:11 BW betrekking heeft op wettelijke aansprakelijkheid 'tout court'. Of dat tot aanpassing van de wettekst zou moeten leiden, is de vraag. ${ }^{11} \mathrm{Ik}$ acht het niet echt nodig en zou blij zijn als de bepaling niet, zoals het wetsvoorstel bestuur en toezicht rechtspersonen wil, wordt weggemoffeld in een onsamenhangende bepaling als het voorgestelde art. 9b samen met - onder meer - het huidige art. 2:131/141 BW inzake de rechterlijke competentie. Deze kwesties hebben weinig met elkaar gemeen.

Rest de buitenlandse rechtspersoon die als bestuurder van een Nederlandse rechtspersoon optreedt. Ik denk dat we eerst eens zouden moeten weten in hoeverre deze figuur problematisch is in het kader van de omzeiling van bestuurdersaansprakelijkheid. Bovendien: geldt niet ook hier dat zij die met een door een buitenlandse rechtspersoon bestuurde Nederlandse rechtspersoon te maken hebben wat meer op hun qui-vive moeten zijn? 